\title{
Intelligent Human Resource Management Using Latent Semantic Analysis with the Internet of Things
}

\author{
Kanokrat Jirasatjanukul, Prachyanun Nilsook, and Panita Wannapiroon
}

\begin{abstract}
The objective of this study is to design a conceptual framework of intelligent human resource management using latent semantic analysis (LSA) with the internet of things (IoT) by using Near Field Communication (NFC) technology and to design the intelligent human resource management architecture using latent semantic analysis with the Internet of Things using NFC. The aim is to develop a prototype in human resource management system development for application in an organization. The research results show that the conceptual framework consists of input in the form of HRM loT LSA. As far as the process is concerned, it was Intelligent Human Resource Management using Latent Semantic Analysis with the Internet of Things to operate in a High Performance Education Organization. The output with regard to the High Performance Education Organization had 4 components: 1) a mobile telephone that had NFC 2) NFC Tag used in imputing the data 3) processing the data by LSA and 4) an application showing the data. The system architecture was divided into 3 main parts: BYOD (Bring Your Own Device), HRM and an HPO Report.
\end{abstract}

Index Terms-Human resource management, latent semantic analysis, internet of things, NFC.

\section{INTRODUCTION}

Technological advancement has changed and developed quickly. The Thai government has specified the policy framework with regard to information technology and communication as a 10-year policy. The first phase was the period of 1996-2000, followed by the period 2001-2010 with the current one being 2011-2020. Entitled Smart Thailand 2020 , it focuses on intelligent development. The business operation in terms of the economy and of society to be based on knowledge and intelligence. People and organizations in every sector realized the importance and the role of ICT to economic and social development that was both environmentally friendly and had a part in the development process. With regard to the said policy, there was a concept of university management called Green University, that involved using information technology to connect information from various parts of an educational organization to analyze and manage the organization systematically [1] by using

Manuscript received January 20, 2019; revised March 12, 2019.

Kanokrat Jirasatjanukul is with Division of Information and Communication Technology for Education, Faculty of Technical Education, King Mongkut's University of Technology North Bangkok, Thailand (e-mail: s5902052956011@email.kmutnb.ac.th,jkanokrat@gmail.com).

Prachyanun Nilsook is with Vocational Education Technology Research Center, King Mongkut's University of Technology North Bangkok, Thailand (e-mail: prachyanunn@kmutnb.ac.th).

Panita Wannapiroon is with Innovation and Technology Management Research Center, King Mongkut's University of Technology North Bangkok Thailand (e-mail: panitaw@kmutnb.ac.th).
Enterprise Resource Planning (ERP) that helped save resources, reduce work operation and help manage organization to progress [2] by connecting information in each aspect of the management of the organization, and to manage the organization systematically. One of the minor aspects of ERP which was however an important component that would help the effective management of an organization and which could lead an organization to achieve its goal was Human Resource Management (HRM). Associated with this and with the advancement of information technology and communication, was the development of a format to manage human resources through the internet entitled e-HRM [3] which would help data management in terms of inspection, searching, and improvement of relevant information to make it more convenient. Through this organizations could access information anywhere and at any time through the internet However, in accessing or recording data such as training data records, activity participation, self-development etc., users had to input data by themselves, and there was always the possibility of mistakes or delays. Nowadays, there is more technology which helps access and manage data more conveniently. Connecting data in daily life is done through an internet network called the Internet of Things (IoT).

The technology of the IoT has the characteristics of connecting and sharing data relating to both living and non-living things, which helps provide convenience in terms of verifying, checking for safety, or providing convenience in controlling various items of equipment as needed [4]. The IoT connects telephones, mobile phones or computers by sending information freely and automatically using wireless technology. There are 4 popular forms of wireless technology in use for sending and receiving data [5] in the form of Infrared Data Association (IrDA), Bluetooth, Radio Frequency Identification tags (RFID) and Near Field Communication (NFC), the last of which is a short range wireless technology which is extremely safe and low cost [6], [7]. Moreover, in related synthesis study results, it was found that NFC apart from payment there were applications in other areas of data management such as use in universities to replace student cards to control class attendance through the use of mobile NFC, or even in medicine by using NFC technology to collect personal information and the health information of patients in order to access information quickly for health cards etc. Therefore, in this research, the idea is to use NFC in managing data as part of the human resource management system.

The management of human resources in conjunction with NFC technology has helped proved convenient in accessing data. However, in managing data so that the information in the system were correct and accurate, and in order to reduce 
repetition of these data, all the data must go through Text Processing. There are many techniques used in Text Processing, but was one technique can analyze the text content and find similarities between words or messages that had similar content meaning without using grammatical criteria. This is Latent Semantic Analysis (LSA). Deewester et al. [8] explained that the analysis of latent semantics by single value separation could solve a problem with regard to words which are written differently but have the same meaning. Consequently, it could be used to find the similarity between words which were written differently but had the same meaning. Previous research, however, has not yet developed a system for those who speak Thai, and there is no classification for the parts of speech (POS) found in this language. As a result, it is difficult to analyze [9]. Moreover, there are many Thai terms that have only one meaning and the system cannot differentiate what messages or words the individual wants to use.

From the source and importance of the aforementioned problems, if we could introduce intelligent human resource management into organizations using latent semantic analysis via the Internet of Things by NFC, it would not just reduce the costs, mistakes or errors associated with data repetition. It would also lead to good and fast communication inside the organization, and would increase efficiency in organizational management. This in turn would lead to the development of a high performance educational organization, and be the prototype for system development. Consequently, the aim of this research was to design the necessary architecture.

\section{OBJECTIVES OF THE RESEARCH}

1) To design a conceptual framework of intelligent human resource management using latent semantic analysis with the Internet of Things using NFC.

2) To design the intelligent human resource management architecture using latent semantic analysis with the Internet of Things using NFC.

\section{RESEARCH OPERATION}

1) To study documents and related research in human resource management, latent semantic analysis, and NFC, and then to analyze the data to create a conceptual framework for the system.

2) To develop the system components from the conceptual framework. This has 3 basic foundations including input, process and output.

3) Develop the architectural design from the conceptual framework of the system.

\section{RESULT}

The research results are divided into 2 parts according to the research objectives. The details are as follows:

\section{A. The Result of the Conceptual Framework of the Intelligent Human Resource Management System Using Latent Semantic Analysis via the Internet of Things Using}

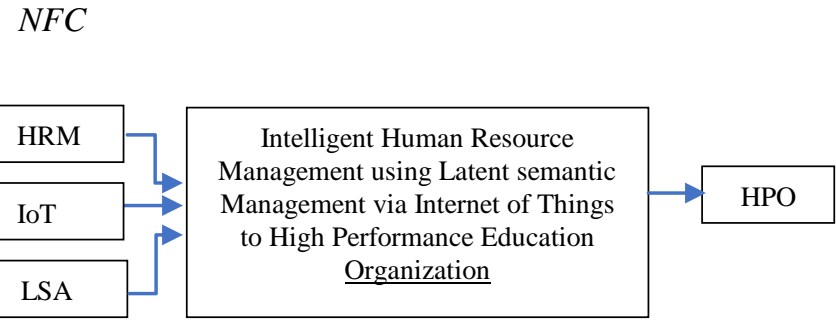

Fig. 1. Conceptual framework.

From Fig. 1 it can be seen that the conceptual framework consists of:

1. input consisting of HRM IoT and LSA

2. process is the system.

3. output consisting of a high performing educational organization.

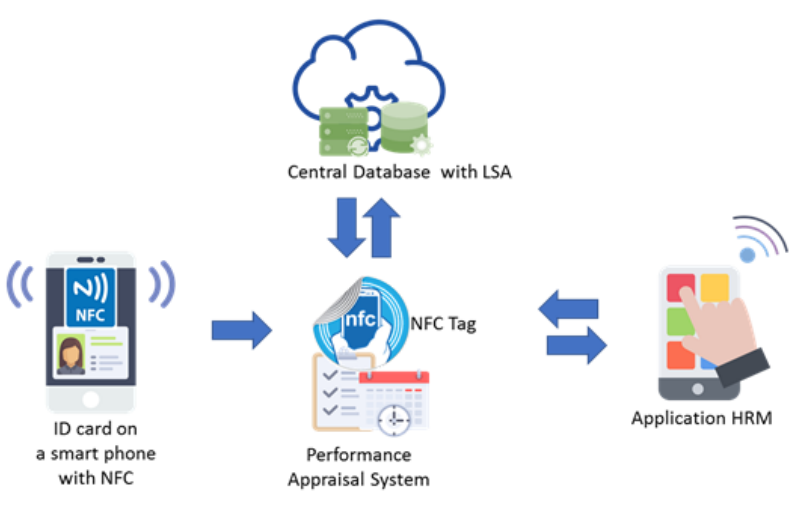

Fig. 2. System components.

From Fig. 2, it can be seen that the system components consist of 4 parts as follows:

1. Mobile telephone in the form of NFC technology to be used to replace personnel ID cards

2. NFC Tags to be used in inputting information such as to use in recording operating time, participating in various activities which in this part would be evidence data.

3. Data collection management system managing semantic data as part of human resource management using mobile NFC technology.

4. Application to be used in showing data such as collecting the personal data of personnel showing such data as work timetables, meetings schedules or various activities that will happen, to report individual workload, etc.

B. The Result of Intelligent System Architectural Design by the Management of Semantic Data via the Internet of Things Using NFC Technology

From Fig. 3 it can be seen that the systems are divided into 3 main parts as follows:

1. BYOD (Bring Your Own Device). To input data, there are two parts involving quantitative and qualitative data. Therefore, the input of data should consist of self-filling out and inputing data via the Internet of Things by NFC Tag. Any equipment could be used in inputing such data.

2. Part of HRM system incorporates data processing which retrieves related information from the Human Resource database which contains both quantitative and qualitative data. Therefore, quantitative data in the form of statistics, would be 
input into the database. As for qualitative data, the latent semantics would be analyzed by LSA and then would go through the process of inspecting work burden agreement.
3. An HPO Report is part of the report showing the results in terms of high performance using educational organizational data.

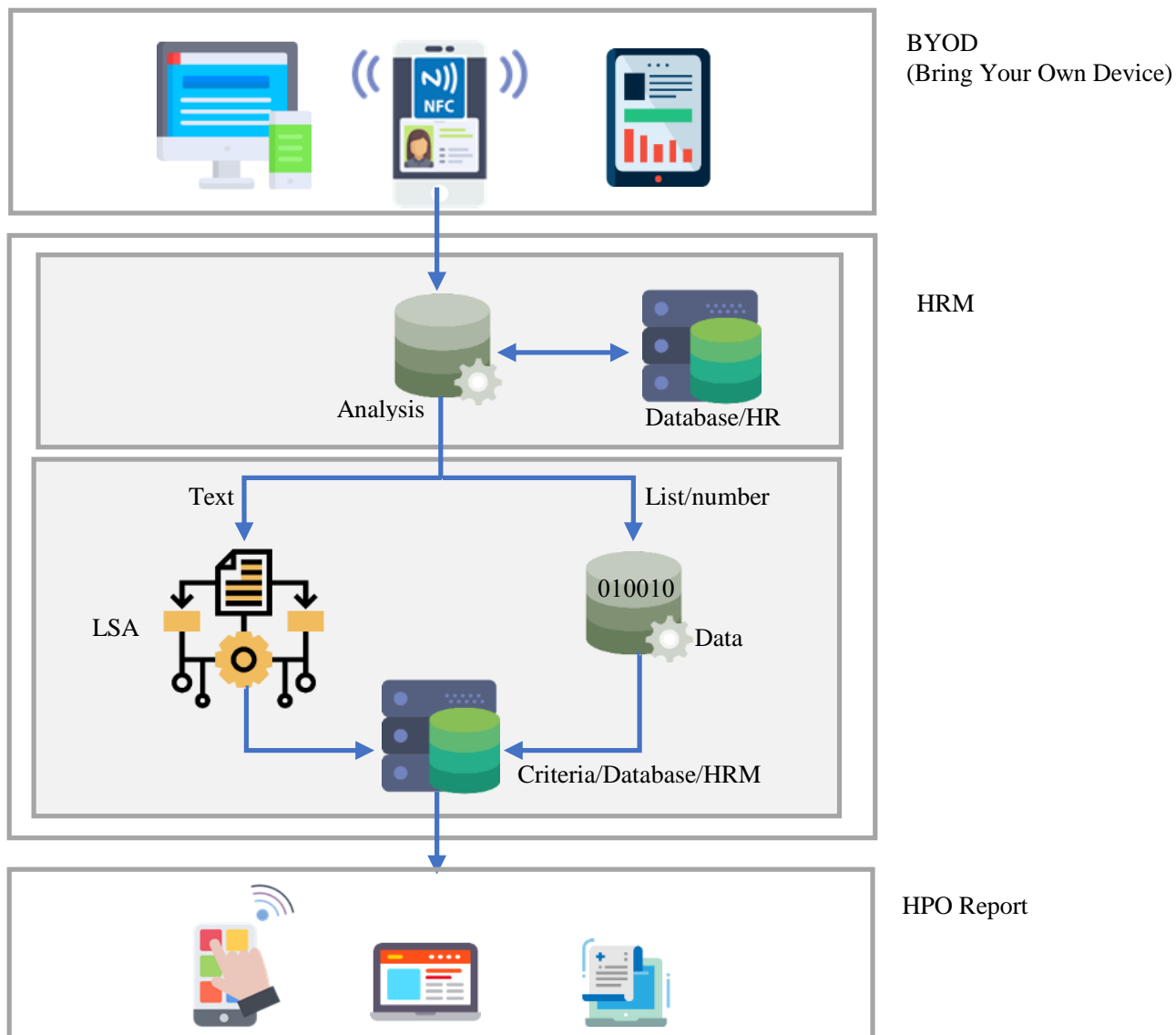

Fig. 3. Architecture of an intelligent human resource management using latent semantic analysis with internet of things using NFC technology

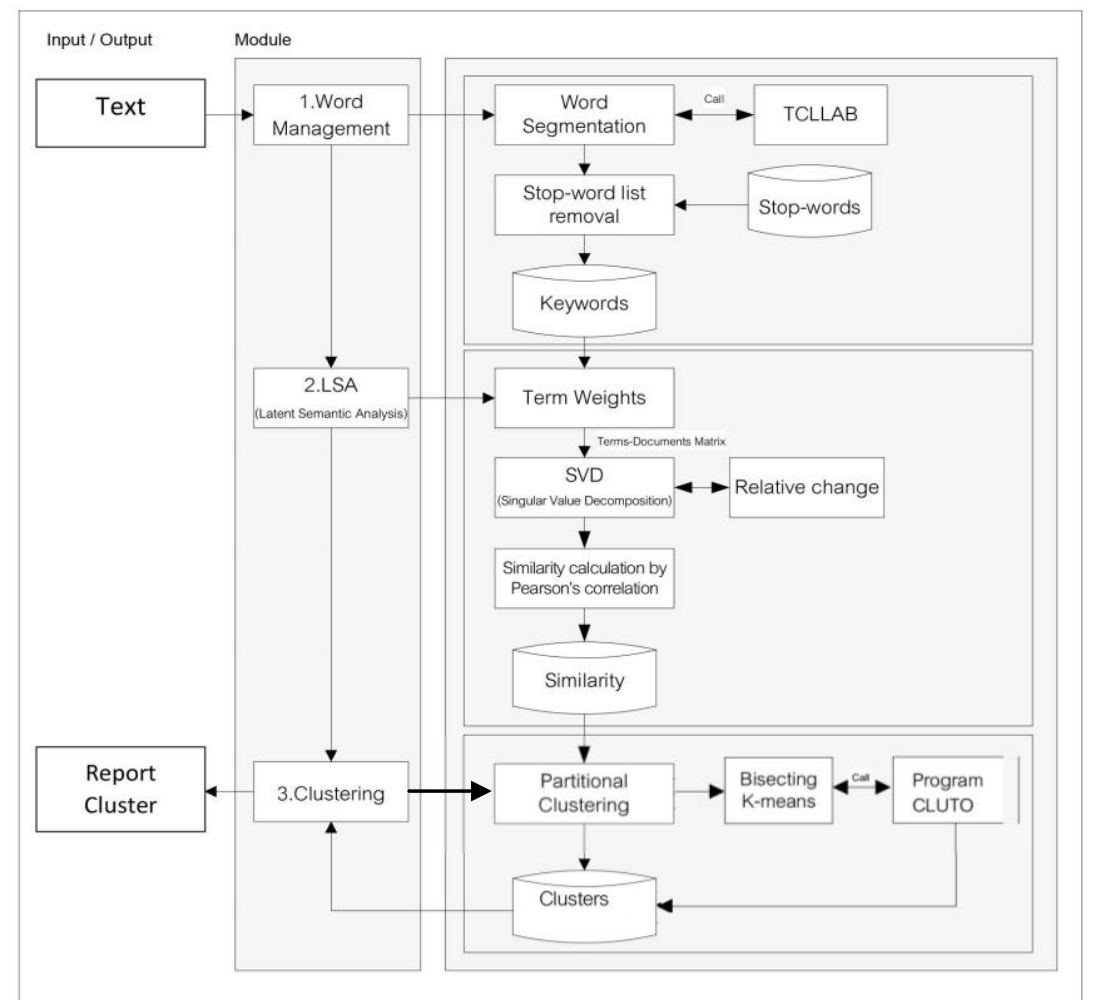

Fig. 4. Module of latent semantic analysis for intelligent human resource management.

From Fig. 4 we can see that the module is divided into 3 modules as follows:
1. Word management including word segmentation entitled TCLLAB for Thai language stop-word list remove to 
keyword.

2. LSA including term weights to form keywords to create a term-document matrix. In addition, the compression/generalization provided by the SVD calculations and similarity calculation by Pearson's correlation results in the creation of a similarity database.

3. Clustering includes partitional clustering by bisecting K-means call using the program CLUTO output to clusters.

\section{CONCLUSIONS}

The research study results in the creation of the architecture for an intelligent human resource management system by using latent semantic analysis via the Internet of Things using NFC. The objective has been to design the conceptual framework which consists of input in the form of HRM IoT LSA. As far as the process is concerned, it takes the form of Intelligent Human Resource Management using latent semantic analysis via the Internet of Things to develop a High Performance Education Organization. and the output was High Performance Education Organization and then would develop the component of concept framework. The system had 4 components as follows: 1) mobile telephones with NFC 2) NFC Tag used in inputing data 3) Data were analyzed by LSA for the Thai Language of Thai word tokenization is sentence segmentation.[10] and 4) Application to show data results and then to design the system architecture. The architecture of the system is divided into 3 main parts in the form of BYOD (Bring Your Own Device), HRM, and HPO Report. This research study was to be a prototype for developing a system for application in an organization to manage human resources by using NFC technology in inputing data, with NFC being used to help reduce costs [6], [7] Moreover, imputing data in this way would reduce mistakes or prevent the overlapping of data, and help communication within the origanization to be smoother and faster. It would also increase the efficiency in terms of organizational management, which would lead to the development of a high level educational organization.

\section{ACKNOWLEDGMENTS}

This research was partially supported by the Graduate Thesis Research Grant (GTRG) from the Graduate College, King Mongkut's University of Technology North Bangkok under award number 134/fiscal year 2561. The researchers would like to express their sincere gratitude to the Vacation Education Technology Research Center of the Science and Technology Research Institute, King Mongkut's University of Technology North Bangkok for supporting this research.

\section{REFERENCES}

[1] J. Nookhong and P. Nilsook, "The analysis of green university resource planning on cloud computing," in Proc. of the Sixth International e-Learning Conf. 2015 (IEC2015), Thailand, 2015.

[2] J. Nookhong and P. Nilsook, "Green university resource planning on cloud computing," International Journal of Information and Education Technology, vol. 7, no. 10, pp. 722-727, 2017.

[3] J. H. Marler and S. L. Fisher, "An evidence-based review of e-HRM and strategic human resource management," Human Resource Management Review, vol. 23, no. 1, pp. 18-36, 2013.

[4] M. H. Maras, "Internet of things: Security and privacy implications," International Data Privacy Law, vol. 5, no. 2, p. 99, 2015.

[5] M. J. L. Fernández, J. G. Fernández, S. R. Aguilar, B. S. Selvi, and R. G. Crespo, "Control of attendance applied in higher education through mobile NFC technologies," Expert Systems with Applications, vol. 40, no. 11 , pp. 4478-4489, 2013.

[6] L. Y. Leong, T. S. Hew, G. W. H. Tan, and K. B. Ooi, "Predicting the determinants of the NFC-enabled mobile credit card acceptance: A neural networks approach," Expert Systems with Applications, vol. 40, no. 14, pp. 5604-5620, 2013

[7] V. Dutot, "Factors influencing near Field Communication (nFC) adoption: An extended TAM approach," The Journal of High Technology Management Research, vol. 26, no. 1, pp. 45-57, 2015.

[8] S. Deerwester, S. T. Dumais, G. W. Furnas, T. K. Landauer, and R. Harshman, "Indexing by latent semantic analysis," Journal of the American Society for Information Science, vol. 41, no. 6, pp. 391-407, 1990.

[9] T. Stergios, S. Demetriadis, and A. Karakostas, "Leveraging conversational agents and concept maps to scaffold students' productive talk," in Proc. of - 2014 International Conf. on Intelligent Networking and Collaborative Systems, IEEE INCoS, 2014, pp. 176-183.

[10] N. Ousirimaneechai and S. Sinthupinyo, "Extraction of trend keywords and stop words from thai facebook pages using character n-Grams," International Journal of Machine Learning and Computing, vol. 8, no. 6, pp. 589-594, 2018.

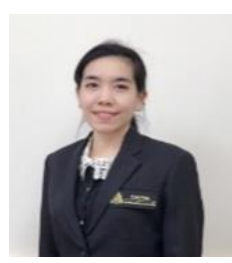

Kanokrat Jirasatjanukul is a Ph.D candidate at the Division of Information and Communication Technology for Education, King Mongkut's University of Technology, North Bangkok (KMUTNB), Thailand.

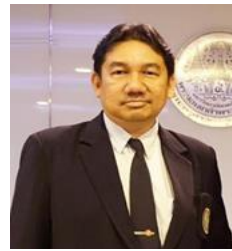

Prachyanun Nilsook is an associate professor at the Division of Information and Communication Technology for Education, King Mongkut's University of Technology, North Bangkok (KMUTNB), Thailand. He currently works in the field of ICT for education. He is a member of the professional society, the Association for Educational Technology of Thailand (AETT).

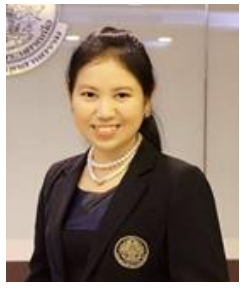

Panita Wannapiroon is an associate professor at the Division of Information and Communication Technology for Education, King Mongkut's University of Technology, North Bangkok (KMUTNB), Thailand. Presently, she works in the field of ICT in education. She is a member of the professional societies, the Apec Learning Community Builders, Thailand (ALCoB) and the Association for Educational Technology of Thailand

(AETT). 